\title{
Justice and Power Relations in Urban Greening: can Lisbon's Urban Greening Strategies lead to more Environmental Justice?
}

\author{
Jessica Verheij* \& Mafalda Nunes
}

Institute of Social Sciences, University of Lisbon, Lisbon, Portugal

Instituto de Ciências Sociais, Universidade de Lisboa, Av. Professor Aníbal de

Bettencourt 9, 1600-189 Lisboa, Portugal

*jessica.verheij@ics.ulisboa.pt

This paper is submitted as candidate for the special issue titled "Energy Infrastructure Transitions and Environmental Governance".

Submitted to the journal Local Environment - The International Journal of Justice and Sustainability on 28 February 2020.

Preprint version. 


\title{
Justice and Power Relations in Urban Greening: can Lisbon's Urban
}

\section{Greening Strategies lead to more Environmental Justice?}

\begin{abstract}
Urban greening has become a prevalent tool in the context of climate change adaptation and mitigation in cities. However, given its uneven social and spatial outcomes, urban greening is increasingly recognized as an environmental justice concern, straightly connected to issues of scale and power. In the framework of Lisbon's election as European Green Capital 2020, this paper examines the city's greening strategies and the related decision-making processes, based on a cross-analysis of the city-wide and longterm vision for urban greening and a localized and relatively unusual planning process for a new green space in the neighborhood of Marvila. Based on qualitative research carried out in-situ, we argue that Lisbon's greening strategies are part of a 'green capital' discourse, which falls short on addressing environmental justice concerns. Focus is placed on global and top-down priorities related to climate change adaptation, and on addressing spatial disparities in green space distribution, while failing to acknowledge the importance of procedural justice aspects related to local recognition and participation. Our findings show how representative and democratic forms of knowledge exchange allow the empowerment and negotiation of multi-scalar urban agendas and, therefore, more inclusive processes of environmental decision-making. By understanding environmental justice as an exercise of multiscalar governance, local solutions can be integrated alongside a comprehensive and long-term vision for green space development.
\end{abstract}

Keywords: environmental justice; urban greening; procedural justice; multiscalar governance; Lisbon

\section{Introduction}

Over the last years, cities started gaining a prominent role in global policy-making, both individually and through influential city-networks of different sorts and sizes (Gordon 2018). Issues related to climate change and environmental sustainability are now addressed at an urban level as well as through national, regional and global-scale action. Within this framework of concerted environmental responses, a particular emphasis is placed on the promotion of urban greening. Cities all over the world are recognizing the value of urban green space, due to its positive impact on urban environments and on the 
quality of life of its inhabitants. Urban greening, whether parks, public gardens, street trees or urban forests, are seen to provide many benefits, ranging from improved air quality to stormwater detention and from improved levels of biodiversity to increased thermal comfort in densely populated environments (Burkart et al. 2016; Graça et al. 2018; Kabisch and Haase 2014). Besides environmental quality, green spaces provide recreational opportunities, contribute to improved mental well-being and provide urban residents with a sense of local identity and belonging (O'Brien et al. 2017; Kabisch and Haase 2014; Oliveira, Vaz, and Andrade 2014). For all those reasons, urban greening has become a prevalent tool for developing cleaner, healthier and more attractive living environments.

Despite the multiple benefits, urban greening is far from a neutral or technical exercise, since it is straightly connected to issues of power and justice. Green space development can have significant social implications, which are often overlooked or deliberately ignored by policy-makers (Haase et al. 2017). Such strategies may exacerbate already existing social inequalities, if access to green space is exclusively improved for those wealthy enough to afford living in proximity to these environmental amenities or if green spaces are conceived without attending to specific contextual needs (Anguelovski 2016; Curran and Hamilton 2018). Previous studies have shown how less privileged and marginalized social groups often experience difficulties in accessing green space and therefore in enjoying its benefits (e.g. Kabisch and Haase 2014; Nesbitt et al. 2019; Wolch, Byrne, and Newell 2014). Given the significant impacts of urban greening strategies at a local and supra-local level, a critical understanding is required of the power relations and justice implications at play. 
This paper explores this perspective by zooming in on the city of Lisbon, Portugal's capital city. In the summer of 2018, Lisbon was elected European Green Capital 2020 by the European Commission, partly due to its efforts to expand and improve the city's Green Infrastructure ${ }^{i}$. Since 2012 Lisbon's master plan includes a system of green corridors through which 400 ha of new green space will be developed by 2022. In spite of such efforts, a recent study in Portugal has provided evidence that green space in the city is not equally accessible for everyone due to significant spatial disparities (Luz et al. 2019). Building on these debates, this paper analyses Lisbon's greening strategies through the lenses of environmental justice, a conceptual approach that aims to expose and understand inequalities in terms of environmental risks and benefits (Schlosberg 2007). We start by providing a brief overview of the literature concerned with environmental justice and its relation to urban greening. We then draw upon qualitative data from research conducted in Lisbon, namely on the city's overall urban greening strategies and on a localized greening process in one of Lisbon's neighborhoods (Marvila). Articulating both cases allows us to take into account the different governance scales and power dynamics that affect local outcomes and decision-making processes. Our research suggests that Lisbon's greening strategies are based on a 'green capital' discourse which falls short on addressing environmental justice concerns. Focus is placed on global and top-down priorities related to climate change adaptation, and on addressing spatial disparities in green space distribution. The strategies fail to acknowledge the importance of procedural justice aspects, related to local recognition and participation. The paper finalizes by showing how environmental justice is ultimately an exercise of multiscalar governance, where local decision-making needs to attend to contextual challenges but also to a long-term sustainability vision at a larger scale. 


\section{Urban Greening from an Environmental Justice Perspective}

Urban greening became an environmental justice concern, due to its often unequal social and spatial outcomes, particularly in terms of access and availability. Patterns of uneven spatial distribution result in limited green space availability for some people, and are frequently related to already existing socio-economic inequalities (O’Brien et al. 2017; Nesbitt et al. 2019; Kabisch and Haase 2014; Wolch, Byrne, and Newell 2014). Besides distance, the physical quality and the lack of safety and adequate equipment of such spaces can present significant obstacles to some social groups (Biernacka and Kronenberg 2018; see also Carmona 2010). Cultural minority groups may abstain from using a green space due to its characteristics not corresponding to their needs or preferences (Kabisch and Haase 2014; Wolch, Byrne, and Newell 2014). In some cases parks can even become sources of conflict between different groups of users over issues of territoriality and ownership (Gidlow and Ellis 2011). Hence, significant parts of the population still find it difficult to gain access to and enjoy the benefits of urban green spaces. Therefore, planners and policy-makers are recommended to not only seek to adjust patterns of uneven distribution, but also to consider a range of other barriers that are preventing access to green space (Brooks and Davoudi 2018).

Although current strategies are based on the assumption that urban greening favours social inclusiveness and cohesion, the pathway between new green space and social benefits is often taken for granted and not evidence-based (Haase et al. 2017). Besides the issues related to access, many scholars are pointing out the dangers of the 'green space paradox', concerning the effect of high-quality green space on property values: if a green space is built, housing prices in adjacent areas go up, possibly leading to displacement and gentrification (Anguelovski 2016; Dooling 2009; Checker 2011). Cities that are "going green" (i.e. those implementing a high number of 
green urban sustainability projects) tend to have increased costs of living with consequences in terms of housing affordability and social equity (Garcia-Lamarca et al. 2019). Moreover, greening initiatives can be endorsed by private developers only to maximize their profits on new development (Curran and Hamilton 2018). Thereby, to develop greening strategies that contribute to environmental justice is not simply about creating more green space. Rather, it requires taking into account the (re)production of social inequalities. In this regard, many scholars have stressed the need to theoretically and empirically address issues of recognition and procedural justice alongside the more common concerns on distributional justice. Only through a broader perspective on structural processes of injustice, we can grasp "the nature of justice as practised and argued over in everyday public life" (Walker 2009, 625).

\section{Procedural Justice in Urban Greening: Issues of Scale and Power}

In our approach to the concept of environmental justice, we refer to David Schlosberg's definition "in which justice is defined as fair and equitable institutional processes of a state" (Schlosberg 2007, 25). While it is crucial to understand the broader sociopolitical processes that (re)produce patterns of uneven distribution and access, research has focused mainly on issues related to distributional justice, whereas aspects regarding procedural justice have too often been side-lined (Walker 2009; Pearsall and Pierce 2017).

According to Schlosberg $(2004,2007)$ and others, fair and equitable processes start with addressing issues of recognition, related to cultural and institutional processes of disrespect, oppression and stigmatization, which devalue some people in comparison to others. Yet, there are several ways in which recognition in the context of environmental justice might be socially and spatially constituted, as misrecognition of 
people is often interconnected with and realised through the misrecognition of places (Walker 2009, 626), thus affecting the maldistribution of environmental amenities.

At the same time, procedural justice relates to the socio-political decisionmaking processes that determines the distribution of environmental costs and benefits. Public participation is central in this process: according to Schlosberg (2007), participatory processes are both an element of and a condition for justice, as these address issues related to institutionalized exclusion, misrecognition and uneven distributional patterns. The inability to access, be recognised and participate in environmental decision-making processes is thus a source of injustice itself, as well as a way of reproducing existing injustices (Agyeman, Bullard, and Evans 2003). These different experiences of injustice are not competing nor contradictory: inequitable distribution, a lack of recognition and limited or ineffective participation all work to produce and reproduce injustice (Schlosberg 2004).

\section{The terms for effective participation}

Lately, resorting to citizen participation has become a common approach in many public policy sectors. This trend is noticeable in the proliferation of a myriad of participatory mechanisms and arrangements such as public hearings, neighbourhood councils, participatory budgets and so on (Bherer 2010; Bandeira and Ferraro 2013; Falanga and Lüchmann 2019). Although these solutions vary in terms of objectives and approach, they all share a similar principle of engaging citizens in decision-making beyond traditional electoral mechanisms (Bherer 2010, 287). The benefits associated with participation go from the promotion of citizens' trust, engagement and support regarding the policy process to broader social goals such as community accountability, empowerment and cohesion. Nevertheless, although citizen participation is now 
increasingly backed up by a broad range of arguments, its implementation has led to feeble and contradictory results (Boonstra and Boelens 2011). On the one hand, participatory practices are often not very convincing due to a weak political will, an ignorance of the requirements of participatory democracy or due to the exploitation of participation to serve other parallel ends (Curry 2012; Bherer 2010; Kinzer 2018). On the other hand, discourses and forms of participatory governance are often seen to downplay the impacts of structural inequalities which ultimately set the 'rules of the game' (Mohan and Stokke 2000; Swyngedouw 2005; Bandeira and Ferraro 2013). The logic behind these democratization processes is, above all, top-down: local participatory movements are encouraged by governments at higher level, for which these movements become part of a multilevel governance game of political legitimization (Bherer 2010). It is thus quite misleading to directly associate citizen participation with a just and equitable process.

Furthermore, managing effective forms of participation in environmental decision-making processes is rather challenging considering the plurality of spatialities which come into play (Walker 2009). Considering the complexity of impacts of green space on different urban scales and over time, "greenspace is not an entirely uncontested and unproblematic 'good thing' that contributes equally for all” (Walker 2009, 621). Instead, its impact shifts across scale - from the neighbourhood to the municipal, regional and global level. As such, participatory processes feeding into procedural justice may very well fail to recognize environmental impacts that transgress the logic of administrative boundaries, for example, if only part of the population impacted by the decision-making process is involved. At the same time, while cities operate in broader political and economic contexts, local authorities are increasingly called to serve multi-scale policy interests based on concerted visions and approaches, 
which may limit to what extent policy implementations do, in fact, contribute to just outcomes at a local level (McKendry 2016).

As cities have augmented their efforts in terms of urban greening in the context of global climate governance, this has brought them into contact with a myriad of external interests and supra-national power structures. Although this may have helped to accelerate the pace, scale and scope of these interventions (for example, with political and financial incentives, such as the European Green Capital and other similar programmes and awards), there remains a need for critical evaluation and careful analysis regarding at what costs and to whose benefit such efforts are implemented (Gordon 2018). A tendency remains to treat city-networks around climate governance "as instances of apolitical coordination, power-free learning and sharing, and positivesum collaboration" (Gordon 2018, 2). Much to the contrary, these translocal sociopolitical spaces are organized around new forms of power, to which Krisch (2017) refers to as "liquid authority", characterized by being open-ended, indeterminate, contingent, dynamic and typically driven by informal relations and institutional multiplicity.

Within this complex governance context, recent scholarship has been arguing that relevant insights regarding the challenges of global climate governance can be drawn by attending to expressions of urban contestation and resistance (Casas-Cortés, Osterweil, and Powell 2008; Curșeu and Schruijer 2017; Kaika 2017; Gordon 2018). Instead of concealing or ignoring existing competing imperatives, these authors claim that acknowledging and focusing the attention in forms of urban dissent may help to excavate and assess the 'liquid' power dynamics at work, as cities decide whether, how and in what ways to govern climate change. Namely it can help to scrutinize the "fundamental tension inherent in the notion of global climate governance undertaken 
by, and through, cities: the need to be both globally meaningful and responsive to local interests and needs" (Gordon 2018, 10). In this respect, over-emphasizing the former may come at a heavy cost to the interests and needs of marginalized places, communities and individuals.

\section{Case Selection and Methodology}

This research analyses Lisbon's urban greening strategies through a cross-analysis of two sources of data. First, we examine the overall and city-wide greening policies, to then zoom in on a peculiar greening process that is taking place in Marvila, a smallscale neighbourhood setting located in Lisbon's eastern riverside. The articulation of these sources of data allows us to draw important conclusions about environmental justice challenges and its implications for urban greening processes in Lisbon. Whereas the municipality is concerned with developing a long-term, encompassing and globally competitive vision and with ensuring even distribution of costs and benefits within the city, the local community in Marvila is pressing for more involvement and participation in decision-making regarding their day-to-day access to environmental amenities.

Despite some discrepancies in terms of priorities, their concerns do overlap and complement each other in relevant ways. As such, analysing both perspectives simultaneously allows for a broader understanding of the gaps and/or inefficiencies of current strategies and approaches, by making visible competing interests and the multiscalar governance aspects of urban greening.

The empirical material is based on qualitative research carried out in two parts.

Firstly, data on Lisbon's city-wide and long-term strategies was collected from planning documents and interviews with experts from the Lisbon's city council $(\mathrm{N}=6)$ carried out by the first author during the period January-May 2019. This resulted in an analysis 
of the priorities of city-wide strategies and how these relate to the issues explored in this study, including the assumptions and knowledge claims on which these strategies are based. The data was coded and analysed in order to generate an understanding of the extent to which social implications and justice-related concerns are integrated into Lisbon's greening strategies.

Additionally, case-specific evidence was collected in the context of the planning process for a new green space in Marvila, during research carried out by the authors for the H2020 project ROCK ("Regeneration and Optimization of cultural heritage in Creative and Knowledge cities”) in the period 2018-2020. Although this planning process is taking place independently from the ROCK project, our role as researchers in the area provided us privileged access to the main local stakeholders and the opportunity to closely follow the development of this ongoing greening process. Hence, this study's findings are based on different moments and sources of data collection, such as document analysis and interviews, but also on on-site observations and notes from participation in meetings and community events. Through participant-observation we sought to gain insights on the local and municipal perspectives and responses regarding issues of access to green space, public participation in green space development and the overall conditions for developing more just greening strategies.

\section{Lisbon's Urban Greening Strategies}

Lisbon's election as European Green Capital 2020 is proof of international recognition of the city's recent efforts in developing sustainability programs, such as its Green Infrastructure. Since 2012, Lisbon's master plan (CML 2012) includes a system of green corridors, which cross the city in order to connect different green spaces, the river waterfront and the urban forest of Monsanto. These green corridors are developed 
through two main objectives: 1) to adapt the existing green space to climate change by mitigating heat waves, heavy rainfall and increased droughts; and 2) to improve access to green space for citizens, by increasing the availability of green space and by improving its points of access (interview with municipal landscape architect, 2019). Through these initiatives, the city is creating 400ha of additional green space in the period 2012-2022, equivalent to an increase of 20\% (CML 2017a). Besides the master plan, two other strategic documents address green space on a city-wide level: the strategy for climate change adaptation (CML 2017b) and the local action plan for biodiversity (CML 2015). The plans emphasize the role of green areas in terms of climate regulation and the provision of ecological ecosystem services - in particular stormwater management and the mitigation of the heat-island effect. By seeking to ensure the continuity and connectivity between green environments, the system of green corridors aims to enhance levels of biodiversity while improving the quantity and quality of ecosystem services. At the same time, the plans stress the need to develop climate-resilient spaces through the selection of vegetation, the design of the landscape and its maintenance. Hereby the plans mainly emphasize the ecological function of green space and its decisive role in scenarios of climate change.

\section{Distributional justice}

Green Infrastructure on city-wide level is thus considered primarily as a measure for climate change adaptation. Nonetheless, the plans do address concerns related to green space availability and how this impacts to what extent people are able to use and interact with urban nature. A recent study by Luz et al. (2019) has provided evidence regarding the uneven distribution of green space in Lisbon: although Lisbon's average green space coverage is $21 \%$, in most zip code areas (12 out of 19) coverage is less than 
$10 \%$, indicating large spatial disparities. Similar findings were published in a municipal report in 2016, which includes an analysis of access to green space based on distance: it states that less than $50 \%$ of Lisbon's population is served by a nearby green space (CML 2016, 43). These spatial disparities are addressed by the system of green corridors, which aims to increase green space availability throughout the city and to connect green environments through pedestrian and cycle paths. Likewise, the dense inner city - with low green space availability - becomes better connected to green areas such as the Monsanto forest and large urban parks. The importance of these new connections was stressed several times during the interviews held with greening experts from the city council. The interviewees showed awareness of the importance of green space in everyday life: one landscape architect underlined the interest of having 'nature at your doorstep'; another highlighted the creation of outdoor gyms in parks.

Nonetheless, findings from the analysis of both the planning documents and the interviews suggest that access is considered to be mainly about distance: is distance to the nearest green space within a predetermined threshold? As distance is easily quantifiable, it is often used as a measure to understand access. However, as previously discussed, access to green space is determined by a number of different barriers of which distance is only one. Other concerns related to the lack of safety, inadequate equipment, poor attractiveness or limited cultural inclusiveness are not taken into account by Lisbon's greening strategies. Although local particularities are difficult to address through city-wide plans and strategies, this one-directional view of access inevitably compromises its impacts in terms of environmental justice. While physical distance to the nearest green space may be reduced, other issues related to accessibility persist. This jeopardizes the extent to which the benefits of urban greening are evenly distributed among places and communities. 


\section{Procedural justice}

The decision-making process regarding urban greening strategies revolves mainly around landscape architects and city architects working in different departments of the city council. The process is led by the councilman for green structure, environment and energy - whom holds this position since 2008 and has been on the forefront of enhancing green space in Lisbon. Technical staff is responsible for developing and implementing the strategies. The office for green structure, constituted mostly by landscape architects is generally responsible for designing the projects for specific green spaces. In some cases this task is outsourced to external parties. Through the interviews with greening experts, it became clear that decision-making is informed mainly by expert knowledge related to landscape architecture and climate change adaptation. In a general way, municipal interventions lack formal and consistent processes of public participation. When asked about public participation in her work, one of the interviewees paused and reflected for a moment - to then reply that there is none (interview with municipal landscape architect, 2019). Decision-making processes are democratic in the sense that decisions taken by the councilman need to be approved by the municipal assembly. Moreover, interviewees stated that an ongoing conversation exists with local stakeholders, such as city districts, housing associations or NGO's. However public consultations are not mandatory nor regular, and mainly organized to 'test' the receptivity of a project with the local population. Recommendations from these consultations may be integrated in the process, but projects are rarely discussed with the local population from the beginning.

Decision-making processes are thus mostly led by landscape architects who define, among other things, the type of uses to be provided and the type of equipment to be included, with little to no engagement of the local populations. Hence, urban 
greening processes are characterized by a rather top-down approach where expert knowledge prevails over "community" or "tacit" knowledge (Haase et al. 2017). This is problematic, for reasons addressed by Madureira et al. (2018), who have assessed citizens preferences regarding green space characteristics in three Portuguese cities, including Lisbon. The authors conclude that no "one-size-fits-all" approach can meet the diversity of needs and desires of local residents, as preferences vary from one city to another but also within cities. Such findings suggest that as long as local knowledge is not taken into account alongside expert knowledge, decision-making outcomes related to urban greening will continue to present feeble and unequitable results. We follow our analysis by exploring how top-down processes are challenged through a grassroots greening project in the neighbourhood of Marvila.

\section{Planning for a new Green Space in Marvila}

In the context of Lisbon's economic growth and its urban regeneration efforts of the last years, the neighbourhood of Marvila - a postindustrial area located in the eastern riverfront of the city - has gained a new socioeconomic dynamic and increased political relevance. Whereas for many years Marvila was seen as an urban enclave and a territorial 'hiatus' in the city ${ }^{\mathrm{ii}}$, characterized by empty factories, derelict buildings and bad reputation social housing estates, today its riverside part is promoted as the new "hip neighbourhood" iii in Lisbon, where everyone wants to invest. The former industrial spaces were occupied by creative industries and the so-called "creative class", while its privileged location, the fragmented land-use planning and the poorly maintained buildings sparked the attention of the booming real estate market. However, in contrast to the economic vitality of riverside Marvila, the upper part of the neighbourhood (mainly constituted by social housing estates) faces many challenges and important 
needs in terms of access to social, economic and environmental goods and services. Two rail lines crossing the neighbourhood, a deficient road network and a poor transportation system, help separating these two very different realities.

Within this context, Marvila has experienced increased political attention, with a series of municipal-led initiatives projects and strategies seeking to contribute to improved urban integration and social inclusion. In particular, there has been a growing interest and concern regarding the future use of the many vacant spaces that exist within Marvila, from abandoned and derelict buildings to vacant land and urban voids. In the absence or insufficiency of qualified public and green spaces in the neighbourhood, these vacant areas are often used by local residents as a playground for kids or as small individual farming plots. In the framework of Marvila's redevelopment and rebranding efforts, new plans start to appear, which include the rehabilitation and reconversion of these spaces into new strategic uses. Namely, for uses that respond to the current priorities of the municipal urban agenda, including housing development but also promoting urban greening - in line with its 2020 European Green Capital agenda.

It is against this background, and as a reaction to the public requalification investments that were mostly targeted at riverside Marvila, that a grassroots community project emerged proposing the creation of a public park and a network of bike lanes in Marvila's social housing area. The project, called "Transformar Marvila com Jardim e Ciclovias" (To transform Marvila with a Garden and Bike lanes), was developed by a local community group called " 4 Crescente", composed of local residents, associations and local institutions. While the planning process that emerged from this proposal is ongoing since 2018, it has led us to question the effectiveness of standard planning approaches in Lisbon's urban greening strategies in terms of ensuring environmental justice. Namely, it has encouraged the assessment of current multi-scalar governance 
challenges and the consideration of alternative and more participated approaches that could contribute to significant policy improvements.

The initiative for the "Transformar Marvila com Jardim e Ciclovias" (TMJC) project emerged during the meetings of the 4 Crescente community group, as a response to a call for proposals to Lisbon's Participatory Budget and to Marvila's parish council Participatory Budget. Both programs exist to finance citizens' ideas, whether at municipal or neighbourhood scale. According to the residents, the main needs in the neighbourhood included the lack of a qualified green space for children to play and for community leisure and social activities. The bike network was included in the proposal to improve the quality and safety of the neighbourhood's mobility system.

The proposal made to the Lisbon Participatory budget was rejected, given its alleged incompatibility with existing municipal plans for the construction of new public housing in the same area. However, the application for the Marvila's parish council Participatory Budget was accepted, under the condition of finding a new area for its implementation. Due to strong citizen mobilization and collaboration, and to a general concerted reaction to the contradictory results of both applications, momentum for the park was built and the local municipal government started to publicly acknowledge the need for a new green space in this part of Marvila. After several meetings held between the local community and representatives from the city council (including a meeting with Lisbon's Mayor in May 2019), the city council agreed to endorse and implement the project in Marvila. A technical team of municipal workers was assigned for this purpose, which agreed to work in close articulation and collaboration with the local population, throughout the project implementation process. The 4 Crescente community group, as the initial project proponent, has firmly stated from the start that the local community should continue to be involved in the design and development of the 
project, alongside the involvement of municipal experts. Nevertheless, despite the initial wins and the apparent good receptiveness for developing a participatory planning process, many challenges appeared when putting participation into practice. Although the city council has publicly demonstrated its support for this initiative, the project has been facing constant setbacks and the local community has to consistently claim the inclusion of their knowledge and vision. The constant delays and the limited interaction and communication from local authorities ended up affecting the residents' trust in the effectiveness of the participatory process.

\section{Negotiating urban greening agendas}

Along with municipal involvement, the TMJC project saw the emergence of a range of requirements, restrictions and contradictions regarding what this garden could become, and the role that citizens could play in this process. The project has interfered with different political agendas from different municipal departments (namely the department for housing and local development, the department for urban planning and the currently reinforced 'green' municipal agenda), leading to internal municipal tensions, increased bureaucracy and delays. Nevertheless, as the project was backed up by higher levels of municipal government, major administrative obstacles were mitigated. In any case, the logic behind the support for this specific project and participatory process appears to be essentially top-down. When it comes to decisionmaking processes, challenges emerged in balancing and articulating the municipal and community's vision. The 4 Crescente community group has taken the initiative to autonomously organize a participatory process in order to have the community's perspective heard and recognized. A series of community meetings were organized and widely promoted within the neighbourhood, in order to reach and engage different local 
actors. In addition, the group organized a survey and a focus group in order to collect the different needs and wishes for this garden (namely the type of equipment needed, the type of vegetation, the design and the accessibility to the garden, etc.). The results from this participatory process were handed over to the municipal technical team to be incorporated in the planning project for the garden. Furthermore, the project and the community's ideas were extensively promoted within and outside the neighbourhood through the participation of 4 Crecente members in public talks about TMJC and interviews for local media. As such, despite the apparent positive municipal receptiveness, effective participation seems to be largely dependent on the existence and efforts of a well-organized group composed of local residents, associations and institutions. Together the 4 Crescente community group gathers the necessary skills, knowledge and resources to formulate their demands clearly and to gain the attention and the recognition of the municipality regarding the value and legitimacy of their claims.

At present, an international call for proposals was launched by Lisbon Municipality (Procedure SRU_20208_CIC) in order to select the project for the garden in Marvila. Following the continuous pressure and efforts from the 4 Crescente community group, a document with the communities' inputs and results from their local participatory process was included as a supporting element for this call. Applicants are required to take this information into account and to include it, as much as possible, in their proposals. Moreover, one representative from the community group was appointed as consultant for the jury (mainly composed of municipal experts) who will be in charge of selecting the winning project for the garden.

Looking at the TMJC urban greening process as a whole, although the transformation of a community-led initiative into an actual city planning project is very 
positive, it is evident that local residents feel the need to continuously uphold the effective recognition of their voice throughout the decision-making process. Such efforts are a clear sign that the current top-down governance approach to urban greening in Lisbon is not acknowledging or responding effectively to local needs neither, in a broader view, to environmental justice concerns. The example of the 4 Crescente community group, which gathers a range of local actors with different profiles, knowledge and skills, managed to reach consensus though horizontal formats of decision-making, namely community meetings, focus groups and surveys. Within this framework, information is openly shared between those involved and different perspectives are allowed to be expressed and incorporated - although not without negotiation and some internal tension. This shows how improved recognition and participation is possible and how it can lead to more inclusive and just results.

\section{Discussion}

In the first place, our research shows that Lisbon's urban greening strategies are based on a logic of expert knowledge, ecological ecosystem services and climate change adaptation principles. This results from a sustainability vision in which Green Infrastructure is considered to play a decisive role in changing climate scenarios. Although climate change adaptation feeds into issues of social justice (e.g. through the concept of climate justice, see, among others, Schlosberg [2012]) the current Lisbon strategies are not sufficiently attending to environmental justice concerns. The distribution of environmental amenities and the subsequent benefits in terms of health and well-being are addressed only from a spatial point of view, seeking to reduce distance to the nearest green space. Through a mostly quantitative analysis, a range of other barriers and obstacles affecting access to green space are left out in these 
strategies. This can be partly explained by the top-down approach to policy development followed in Lisbon, in which issues related to procedural justice tend to be undervalued - namely when it comes to the recognition and participation of nonexpert knowledge and interests in decision-making processes. Environmental justice requires technical experts to recognize the value of attending to different sources of knowledge, for improving decision-making processes at the local level (Haase et al. 2017). Moreover, they need to find ways to articulate and to combine broader visions and interests with the context-specific perspective of lay stakeholders through processes of public participation (Curran and Hamilton 2018; Wolch, Byrne, and Newell 2014). While public participation processes are no longer uncommon for most local governments, the methods that are used to bring forth citizen involvement and participation in decision-making are still largely based on government preconditions (Bherer 2010; Boonstra and Boelens 2011; Bandeira and Ferraro 2013). In the case of Marvila, the TMJC project faced a range of requirements, restrictions and contradictions regarding what this garden could become, and the role of the local community in the decision-making process. In fact, policy-makers seem to be hardly able to think beyond the confines and path-dependencies of traditional top-down formats of policy-making and rather incapable of dealing with or making productive use of diversity and conflicting views. Instead policies are preferably standard, uniform guidelines for conduct, to which large groups of actors must submit themselves (Boonstra and Boelens 2011, 117). The resistance from the community group to submit to this top-down logic and their efforts for more recognition and integration of community's knowledge throughout this process, stresses that decision quality tends to increase when the visions and interests of different stakeholders are allowed to be expressed (Curșeu and Schruijer 2017). 
What the case of TMJC also teaches us, is that putting effective forms of participation into practice goes beyond implementing programs and mechanisms such as the Participatory Budget. Rather it requires a long-term commitment from public authorities and local communities to create truly democratic and representative platforms, in order to uphold dialogue and negotiation between different interested parts (Bandeira and Ferraro 2013). Mere public endorsement of a community's initiative and the traditional governmental formats of participatory decision-making do not automatically lead to equitable and just results. Although effective participation makes decision-making more complex - since it involves the recognition and conciliation of various spatial practices, identifications and forms of belonging and is likely to induce conflict - a productive use of heterogeneity and diversity is key since urban places and communities are also intrinsically diverse (Curry 2012; Inch 2012; Bandeira and Ferraro 2013). In this particular case, the strength and effectiveness of the 4 Crescente community group to make its voice heard lays in its horizontal nature and structure as knowledge exchange platform. Within the format of the community group, residents, local institutions and associations can express their concerns and ideas for the neighbourhood and contribute equally (through constant negotiation within the group and with local authorities) to decision-making processes, thus increasing the representation capacity of different interest groups. These forms of dialogue and community involvement are rather uncommon and still undermined in Lisbon's urban greening strategies. Hence, its potential to contribute to improved environmental justice remains unrealized.

Nevertheless, within the current global urban arena these processes and political choices should not simply be viewed from the local level, but as "part of a multilevel governance game of political legitimation" (Bherer 2010, 301; see also Mohan and 
Stokke 2000; Swyngedouw 2005; Falanga and Lüchmann 2019). Governments all over the world are encouraging both 'green' and 'participatory' movements. In this sense, much of the achievements of the TMJC project may be better understood by considering Lisbon's strategic positioning through global interurban competition and policy boosterism, where "green" and "sustainable" cities compete among each other for attracting mobile capital, businesses, highly-educated workers and tourists (McCann 2013; Bradley, Hult, and Cars 2013; Garcia-Lamarca et al. 2019). Within the context of Lisbon as European Green Capital 2020, the TMJC project comes at a time where the city is particularly concerned with publicly promoting its commitment to urban greening. Municipal investment in urban greening is showcased as 'good for everyone', by responding to global concerns related to climate change and urban sustainability. However, the local impacts and significant justice implications of these global policies such as displacement, social exclusion, the disruption of community dynamics and the uneven access to public services and equipment - are left out of the formula. Hence, the Lisbon case confirms the argument made by Sareen and Grandin (2019), that the European Green Capital award is constructed around a discourse that encourages European cities to compete over urban sustainability initiatives, while failing to incorporate environmental justice concerns. This is a recurrent theme when examining the agendas of previous European Green Capitals: an analysis of Stockholm's sustainability strategies and visions following its election as the first European Green Capital in 2010, stresses the need for more fundamentally addressing political concerns (Bradley, Hult and Cars 2013). Furthermore, a meta-analysis of Green Infrastructure development in European Green Capitals shows how discourses used by the winning cities revolve around green economic growth and eco-innovation, while focusing on Green Infrastructure in a "largely one-dimensional direction" (Gulsrud et al. 2017, 252). 
Hence, alternative interpretations of what it means to be a 'green city' tend to be discouraged, with significant implications for action at local level (Gulsrud et al. 2017). While agenda-setting and policy-steering occurs at EU level, local-based action is required to translate these policy discourses into concrete outcomes. The local grassroots initiative in Marvila was able to advance its claims for more green space by 'riding the wave' of the European Green Capital 2020. While cities and city-networks are often placed outside of the local political domain (Gordon 2018) our analysis of urban greening in Lisbon shows how a global political agenda has a strong impact on local contexts and policy processes and how its principles and approaches are enacted and negotiated locally by the different actors involved.

However, despite this inherent tension between large-scale political projects and small-scale contextual needs, that does not mean that decisions made at a local scale are necessarily better or more just than the ones made at a municipal, national or supranational scale. The TMJC process reinforces Purcell's (2006) argument about the "local trap", by showing that the outcomes of a particular scalar arrangement are contingent and its results are dependent on the specific agendas that are empowered (or not) by that specific scalar arrangement, through 'liquid' and relational forms of authority (Krisch 2017). In this particular case, which confronts and intersects global, municipal and local agendas, we understand how through resistance, articulation and negotiation, the local agenda of the 4 Crescente community group, was empowered and able to contribute to the decision-making process.

Environmental justice is thus necessarily an exercise of multiscalar governance (Walker 2009) where local decision-making needs to attend to contextual challenges but also to a comprehensive sustainability vision at a larger scale. The recognition of the local needs of places and communities and inclusive participatory processes should seek 
to communicate and interact with wider municipal and global concerns, through effective and democratic forms of multiscalar governance.

\section{Conclusion}

As cities perform a growing role in global policy-making, it is tempting to understand local governments and the local scale as the most suited to address issues related to environmental justice. Nonetheless, our research suggests that local urban greening strategies often fail to adequately incorporate justice concerns, as some policy aspects and governance scales are prioritized over others. In the case of Lisbon's greening strategies, focus is placed on discrepancies in terms of spatial distribution of green space. This aspect of environmental justice, although being essential, is easily quantifiable and thus more prone to be considered and addressed by city-wide strategies. However, less quantifiable but equally important aspects related to procedural justice, such as issues of recognition and public participation, seem to be undervalued or neglected by local policymakers. Although sporadic mechanisms and formats for public participation are in place, like the Participatory Budget and municipal assemblies, these are insufficient to meaningfully and consistently involve local communities in decision-making processes related to urban greening. The TMJC process and the resistance of the 4 Crescente community group to submit to dominant top-down governance logics shows how the establishment of a democratic platform to foster knowledge exchange and negotiation between different actors and governance scales can offer a powerful contribution to environmental justice.

However, as urban greening is essentially a multiscalar concern, with implications that spread from the local to the global level, local solutions and participatory processes should refrain from replacing a comprehensive and long-term 
vision for green space development. Rather, addressing justice implications in a meaningful way requires a better recognition by policy-makers on how global ideas on urban sustainability impact local-based action and vice-versa and, therefore, how different perspectives and agendas should be empowered to participate in decisionmaking processes. Further research is required to explore how to design effective forms of public participation that can consistently challenge established power dynamics in urban governance processes in order to advance environmental justice. Moreover, procedural justice concerns should be further acknowledged, not only on a local level but particularly at a global scale. Incentives such as the European Green Capital Award are a good starting point for refocusing dominant approaches to urban greening, currently centred on 'green growth' and 'innovation', towards procedural justice, giving it the attention it requires.

Funding: This work was supported by the Horizon 2020 framework of the European Commission under Grant 730280.

Disclosure statement: No potential conflict of interest was reported by the authors.

\section{References}

Agyeman, Julian, Robert Doyle Bullard, and Bob Evans. 2003. Just Sustainabilities Development in an Unequal World. London: Earthscan.

Anguelovski, Isabelle. 2016. "From Toxic Sites to Parks as ( Green ) LULUs? New Challenges of Inequity, Privilege , Gentrification , and Exclusion for Urban Environmental Justice.” Journal of Planning Literature 31 (1): 23-36. https://doi.org/10.1177/0885412215610491.

Bandeira, Pablo, and Augustín Ferraro. 2013. "Integrating Participatory Institutions into the Traditional Representative and Bureaucratic Model of Public Governance." November 28, 2013. 
Bherer, Laurence. 2010. "Successful and Unsuccessful Participatory Arrangements: Why Is There a Participatory Movement at the Local Level?" Journal of Urban Affairs 32 (3): 287-303. https://doi.org/10.1111/j.1467-9906.2010.00505.x. Biernacka, Magdalena, and Jakub Kronenberg. 2018. "Classification of Institutional Barriers Affecting the Availability, Accessibility and Attractiveness of Urban Green Spaces." Urban Forestry \& Urban Greening 36: 22-33. https://doi.org/10.1016/j.ufug.2018.09.007.

Boonstra, Beitske, and Luuk Boelens. 2011. "Self-Organization in Urban Development: Towards a New Perspective on Spatial Planning." Urban Research and Practice 4 (2): 99-122. https://doi.org/10.1080/17535069.2011.579767.

Bradley, Karin, Anna Hult, and Göran Cars. 2013. "From Eco- Modernizing To Political Ecologizing - Future Challenges for the Green Capital.” In Sustainable Stockholm : Exploring Urban Sustainability in Europe's Greenest City, edited by Jonathan Metzger and Amy Rader Olsson, 168-94. Routledge.

Brooks, Elizabeth, and Simin Davoudi. 2018. "Greenspace and Environmental Justice : The Case of Newcastle upon Tyne." People, Place and Policy 12 (2): 118-36. https://doi.org/10.3351/ppp.2018.3835242525.

Burkart, Katrin, Fred Meier, Alexandra Schneider, Susanne Breitner, Paulo Canário, and Maria João Alcoforado. 2016. "Modification of Heat-Related Mortality in an Elderly Urban Population by Vegetation (Urban Green) and Proximity to Water (Urban Blue): Evidence from Lisbon, Portugal." Environmental Health Perspectives 124 (7): 927-34. https://doi.org/10.1037/0022-3514.87.3.293.

Carmona, Matthew. 2010. "Contemporary Public Space: Critique and Classification, Part One: Critique.” Journal of Urban Design 15 (1): 123-48. https://doi.org/10.1080/13574800903435651.

Casas-Cortés, María Isabel., Michal. Osterweil, and Dana E. Powell. 2008. "Blurring Boundaries: Recognizing Knowledge-Practices in the Study of Social Movements." Anthropological Quarterly 81 (1): 17-58. https://doi.org/10.1353/anq.2008.0006.

Checker, Melissa. 2011. "Wiped Out by the 'Greenwave': Environmental Gentrification and the Paradoxical Politics of Urban Sustainability." City \& Society 23 (2): 210-29. https://doi.org/10.1111/j.1548-744X.2011.01063.X.I. 
CML (Câmara Municipal de Lisboa). 2012. Plano Diretor Muncipal - Relatório da proposta de plano [Municipal Master Plan - Report of the plan proposal].

CML (Câmara Municipal de Lisboa). 2015. Plano de Ação Local para a Biodiversidade em Lisboa [Local action plan for biodiversity in Lisbon].

CML (Câmara Municipal de Lisboa). 2016. Relatório de Estado de Ordenamento do Território [Monitoring report on spatial planning]. Departamento de Planeamento.

CML (Câmara Municipal de Lisboa). 2017a. "Lisbon 2020 Application". European Commission.

http://ec.europa.eu/environment/europeangreencapital/winningcities/2020lisbon/15210-2/.

CML (Câmara Municipal de Lisboa). 2017b. Estratégia Municipal de Adaptação às Alterações Climáticas [Municipal strategy for climate change adaptation].

Curran, Winifred, and Trina Hamilton. 2018. Just Green Enough - Urban Development and Environmental Gentrification. London and New York: Routledge.

Curry, Nigel. 2012. "Community Participation in Spatial Planning: Exploring Relationships between Professional and Lay Stakeholders." Local Government Studies 38(3): 345-66.

Curșeu, Petru Lucian, and Sandra GL Schruijer. 2017. "Stakeholder Diversity and the Comprehensiveness of Sustainability Decisions: The Role of Collaboration and Conflict." Current Opinion in Environmental Sustainability 28: 114-20. https://doi.org/10.1016/j.cosust.2017.09.007.

Dooling, Sarah. 2009. "Ecological Gentrification: A Research Agenda Exploring Justice in the City." International Journal of Urban and Regional Research 33 (3): 621-39. https://doi.org/10.1111/j.1468-2427.2009.00860.x.

European Commission. 2013. "Green Infrastructure (GI) — Enhancing Europe's Natural Capital." In Communication from the Commission to the European Parliament, the Council, the European Economic and Social Committee and the Committee of the Regions.

. 2015. "Towards an EU Research and Innovation Policy Agenda for NatureBased Solutions \& Re-Naturing Cities." Publications Office of the European Union. https://doi.org/10.2777/765301. 
Falanga, Roberto, and Lígia H. H. Lüchmann. 2019. "Participatory Budgets in Brazil and Portugal : Comparing Patterns of Dissemination.” Policy Studies.

Garcia-Lamarca, Melissa, Isabelle Anguelovski, Helen Cole, James JT Connolly, Lucía Argüelles, Francesc Baró, Stephanie Loveless, Carmen Pérez del Pulgar Frowein, and Galia Shokry. 2019. "Urban Green Boosterism and City Affordability: For Whom Is the 'Branded' Green City?” Urban Studies, December, 1-23. https://doi.org/10.1177/0042098019885330.

Gidlow, Christopher James, and Naomi Jane Ellis. 2011. "Neighbourhood Green Space in Deprived Urban Communities : Issues and Barriers to Use." Local Environment 16 (10): 989-1002. https://doi.org/10.1080/13549839.2011.582861.

Gordon, David J. 2018. "Global Urban Climate Governance in Three and a Half Parts: Experimentation, Coordination, Integration (and Contestation).” Wiley Interdisciplinary Reviews: Climate Change 9 (6): 1-15. https://doi.org/10.1002/wcc.546.

Haase, Dagmar, Sigrun Kabisch, Annegret Haase, Erik Andersson, Ellen Banzhaf, Francesc Baró, Miriam Brenck, et al. 2017. "Greening Cities - To Be Socially Inclusive? About the Alleged Paradox of Society and Ecology in Cities.” Habitat International 64: 41-48. https://doi.org/10.1016/j.habitatint.2017.04.005.

Inch, Andy. 2012. 'Creating 'a Generation of NIMBYs'? Interpreting the Role of the State in Managing the Politics of Urban Development." Environment and Planning C: Government and Policy 30 (3): 520-35. https://doi.org/10.1068/c11156.

Kabisch, Nadja, and Dagmar Haase. 2014. "Green Justice or Just Green? Provision of Urban Green Spaces in Berlin, Germany." Landscape and Urban Planning 122: 129-39. https://doi.org/10.1016/j.landurbplan.2013.11.016.

Kaika, Maria. 2017. “'Don’t Call Me Resilient Again!’: The New Urban Agenda as Immunology ... or ... What Happens When Communities Refuse to Be Vaccinated with 'Smart Cities' and Indicators." Environment and Urbanization 29 (1): 89-102. https://doi.org/10.1177/0956247816684763.

Kinzer, Kirsten. 2018. "How Can We Help? An Exploration of the Public's Role in Overcoming Barriers to Urban Sustainability Plan Implementation.” Sustainable 
Cities and Society 39 (March): 719-28.

https://doi.org/10.1016/j.scs.2018.02.028.

Krisch, Nico. 2017. "Liquid Authority in Global Governance.” International Theory 9 (2): 237-60. https://doi.org/10.1017/S1752971916000269.

Luz, Ana Catarina, Maartje Buijs, Cristiana Aleixo, Inês Metelo, Filipa Grilo, Cristina Branquinho, Margarida Santos-Reis, and Pedro Pinho. 2019. "Should I Stay or Should I Go? Modelling the Fluxes of Urban Residents to Visit Green Spaces." Urban Forestry and Urban Greening 40 (January): 195-203. https://doi.org/10.1016/j.ufug.2019.01.009.

Madureira, Helena, Fernando Nunes, José Oliveira, and Teresa Madureira. 2018. "Preferences for Urban Green Space Characteristics: A Comparative Study in Three Portuguese Cities." Environments 5 (2): 23. https://doi.org/10.3390/environments5020023.

McCann, Eugene. 2013. "Policy Boosterism, Policy Mobilities, and the Extrospective City." Urban Geography 34 (1): 5-29. https://doi.org/10.1080/02723638.2013.778627.

McKendry, Corina. 2016. "Cities and the Challenge of Multiscalar Climate Justice: Climate Governance and Social Equity in Chicago, Birmingham, and Vancouver." Local Environment 21 (11): 1354-71. https://doi.org/10.1080/13549839.2015.1116064.

Mohan, Giles, and Kristian Stokke. 2000. "Participatory Development and Empowerment: The Dangers of Localism.” Third World Quarterly 21 (2): 24768. https://doi.org/10.1080/01436590050004346.

Nesbitt, Lorien, Michael J Meitner, Cynthia Girling, Stephen R J Sheppard, and Yuhao Lu. 2019. "Who Has Access to Urban Vegetation? A Spatial Analysis of Distributional Green Equity in 10 US Cities." Landscape and Urban Planning 181: 51-79. https://doi.org/10.1016/j.landurbplan.2018.08.007.

O’Brien, Liz, Rik De Vreese, Anton Stahl Olafsson, Tuija Sievänen, Michael Brennan, Mercedes Sánchez, Thomas Panagopoulos, et al. 2017. "Social and Environmental Justice: Diversity in Access to and Benefits from Urban Green Infrastructure - Examples from Europe." In The Urban Forest - Cultivating Green Infrastructure for People and the Environment, edited by David Pearlmutter, Carlo Calfapietra, Roeland Samson, Liz O’Brien, Silvija Krajter 
Ostoić, Giovanni Sanesi Rocío, and Alonso del Amo. Springer International Publishing. https://doi.org/10.1007/978-3-319-50280-9.

Oliveira, Sandra, Teresa Vaz, and Henrique Andrade. 2014. "Perception of Thermal Comfort by Users of Urban Green Areas in Lisbon." Finisterra 50 (98): 113-31. https://doi.org/10.18055/Finis6464.

Pearsall, Hamil, and Joseph Pierce. 2017. “A Spoiled Well (of Data): Addressing the Procedural Injustice of Contemporary Environmental Justice Research through Collaborative Qualitative Data Gathering." Local Environment. Routledge. https://doi.org/10.1080/13549839.2016.1196349.

Purcell, Mark. 2006. "Urban Democracy and the Local Trap." Urban Studies 43 (11): 1921-41.

Sareen, Siddharth, and Jakob Grandin. 2019. "European Green Capitals : Branding, Spatial Dislocation or Catalysts for Change ?" Geografiska Annaler: Series B, Human Geography, 1-17. https://doi.org/10.1080/04353684.2019.1667258.

Schlosberg, David. 2004. "Reconceiving Environmental Justice: Global Movements and Political Theories." Environmental Politics 13 (3): 517-40. https://doi.org/10.1080/0964401042000229025.

- 2007. Defining Environmental Justice - Theories, Movements, and Nature. Oxford: Oxford University Press.

—. 2012. "Framework for Adaptation Policy." Ethics \& International Affairs, 26 (4): 445-61. https://doi.org/10.1017/S0892679412000615.

Swyngedouw, Erik. 2005. "Governance Innovation and the Citizen: The Janus Face of Governance-beyond-the-State." Urban Studies. https://doi.org/10.1080/00420980500279869.

Walker, Gordon. 2009. "Beyond Distribution and Proximity: Exploring the Multiple Spatialities of Environmental Justice.” In Antipode, 41:614-36. https://doi.org/10.1111/j.1467-8330.2009.00691.x.

Wolch, Jennifer R, Jason Byrne, and Joshua P Newell. 2014. "Urban Green Space, Public Health, and Environmental Justice : The Challenge of Making Cities ‘ Just Green Enough ."' Landscape and Urban Planning 125: 234-44. https://doi.org/10.1016/j.landurbplan.2014.01.017. 
${ }^{i}$ Green Infrastructure is defined by the EU as "a strategically planned network of natural and semi-natural areas with other environmental features designed and managed to deliver a wide range of ecosystem services" (European Commission 2013, 3). The European Union has been playing an important role in endorsing and advocating urban greening, calling for planners and policy-makers to "'re-nature cities" (European Commission 2015) and promoting Green Infrastructure solutions in urban settings.

ii See 'Parque verde vai ligar a zona oriental de Lisboa', available at: https://www.timeout.pt/lisboa/pt/coisas-para-fazer/parque-verde-vai-fazer-a-ligacao-quefalta-a\%20zona-oriental-de-lisboa (accessed 8/2/2019).

iii See 'Move to Marvila, Lisbon's hip neighbourhood', available at: https://www.thetimes.co.uk/article/move-to-marvila-lisbons-hip-neighbourhoodbdhns805k (accessed 01/10/2019) 